\title{
ELABORACIÓN DE UN ENLATADO DE CARNE DE CONEJO (Leporidae)TIPO TROCEADO
}

\section{Clemente Granados-Conde ${ }^{1}$, Miladys Torrenegra-Alarcón², Candelaria Nahir Tejada-Tovar ${ }^{3}$}

${ }^{1}$ Grupo de investigación Ingeniería, Innovación, Calidad Alimentaria y Salud (INCAS). Universidad de Cartagena, Cartagena, Colombia.

2 Grupo de Investigación de Nano, Biotecnología e Innovación (GIBEI). Centro de Comercio y Servicios, Regional Bolívar (SENA), Cartagena, Colombia.

${ }^{3}$ Grupo de investigación en diseño de procesos y aprovechamiento de biomasas -IDAB- Universidad de Cartagena, Cartagena, Colombia.

\section{Resumen}

Se elaboró un enlatado a partir de carne de conejo Nueva Zelanda Blanco, determinando su composición proximal, propiedades fisicoquímicas y funcionales. El producto se formuló y estandarizó empleando trozos de carne de conejos, aditivos e ingredientes, almacenándose a $4^{\circ} \mathrm{C}$ por 3 horas. Se evaluó el producto terminado mediante pruebas microbiológicas y sensoriales. La caracterización fisicoquímica de la carne de conejo confirma las numerosas ventajas sobre el resto de carne de diferentes especies, debido a su elevado contenido en potasio $490 \mathrm{mg}$, igualmente cabe destacar los bajos niveles de sodio que presenta, lo que la hace una carne idónea para dietas con estas especificaciones en minerales. Los recuentos microbianos mostraron un resultado negativo, la evaluación sensorial reveló un nivel alto de aceptación, principalmente en atributos como el sabor y el olor. Concluyendo que la carne de conejo posee un alto valor nutritivo transformándose en una alternativa a la proteína animal para el consumo humano.

Palabras clave: Carne de conejo, enlatado, propiedades fisicoquímicas, propiedades funcionales.

\section{DEVELOPMENT OF A RABBIT MEAT CANNING (Leporidae) TYPE CUTTING}

\section{Abstract}

He was a canning from meat New Zealand White rabbits, determining its proximate composition, physico-chemical and functional properties. The product was made 
53

and standardized using meat of rabbits, additives and ingredients, be stored at $4{ }^{\circ} \mathrm{C}$ for 3 hours. It evaluated the product finished by testing microbiological and sensory. Physico-chemical characterization of rabbit meat confirms the numerous advantages over the rest of meat of different species, due to its high content of potassium 490 $\mathrm{mg}$, also fits highlight low levels of sodium that presents, what makes a suitable diets to meat with these specifications in minerals. Microbial counts showed a negative result, the sensory evaluation revealed a high level of acceptance, mainly in attributes such as taste and smell. Concluding that rabbit meat has a high nutritional value, becoming an alternative to animal protein for human consumption.

Keywords: Rabbit meat, canning, physicochemical, functional properties.

*Para citar este artículo: Granados-Conde C, Torrenegra-Alarcón M, Tejada-Tovar CN.Elaboraciòn de un enlatado de carne de conejo (Leporidae) tipo troceado. Revista Bistua. 2016.14(2):52-57

+ Autor para el envió de correspondencia y la solicitud de las separatas: Granados-Conde C. Grupo de investigación Ingeniería, Innovación, Calidad Alimentaria y Salud (INCAS). Universidad de Cartagena, Cartagena , Colombia. e-mail:clementecondeg@gmail.com 


\section{Introducción}

La calidad de la carne tradicionalmente está determinada por aspectos sensoriales como la apariencia, textura, aroma y sabor; pero otros factores como el valor nutritivo y la seguridad alimentaria han cobrado gran importancia. La estrecha relación entre la dieta y la salud ha conducido a cambios en los hábitos del consumidor, exigiendo productos que respondan a sus preferencias alimentarias $y$ nutricionales. En este contexto, la carne de conejo es muy valorada por sus propiedades nutricionales $y$ dietéticas, es una carne magra, con un bajo contenido de grasa y con menor contenido en ácidos grasos saturados y colesterol que otras carnes (1-3). De ahí se deriva la importancia de conocer el valor nutricional y examinar las posibilidades de la carne de conejo producido como alimento funcional. Sin embargo, se considera que el consumo de carne de conejo en Colombia está limitado debido a factores culturales como: el desconocimiento de las virtudes de esta carne entre los consumidores, la inexperiencia de como procesarlas y la ideología de ver al conejo como una especie solo utilizada para mascotas.

Por lo cual el presente trabajo de investigación tuvo como objetivo elaborar un enlatado de carne de conejo (Leporidae) tipo troceado para demostrar su importancia nutricional e industrial como fuente alterna de nutrientes para el ser humano.

\section{MATERIALES Y MÉTODOS}

La carne de conejo Nueva Zelanda blanco fue suministrada por la Granja la Catalunya "Conejos del Tominé" (Bogotá), las muestras se limpiaron, deshuesaron y almacenadas en bolsas selladas debidamente identificadas.

Los contenidos de fibra cruda, humedad, cenizas, grasa, proteína y $\mathrm{pH}$ se determinaron según la metodología descrita Morillas y Delgado(4).

\section{Determinación de minerales}

Las muestras secas y calcinadas (cenizas) fueron tratadas con $\mathrm{HCl}$ de acuerdo al método recomendado por la AOAC. Los minerales $\mathrm{Na}^{+}, \mathrm{Fe}^{2+} \mathrm{y}$ $\mathrm{K}^{+}$, se determinaron por espectrofotometría de absorción atómica(4).

\section{Propiedades funcionales}

Fueron evaluadas dos propiedades funcionales descritas a continuación:

\section{Capacidad de retención de agua (CRA)}

Se realizó utilizando el método a presión en papel filtro para análisis cuantitativo de $110 \mathrm{~mm}$ de diámetro. Se calculó la capacidad de retención de agua como porcentaje de agua expedida ${ }^{1}$.

Capacidad emulsionante (CE) 
55

Se empleó la técnica descrita por Webb et al.(5). La CE se calculó en $\mathrm{mL}$ de aceite gastado por $\mathrm{g}$ de carne utilizada.

\section{Elaboración del producto enlatado}

El producto enlatado se elaboró mediante el siguiente procedimiento: adecuación, limpieza y troceado de la carne de conejo, posteriormente se calculó las cantidades de los ingredientes. De igual manera, se preparó la salmuera empleando como ingredientes sal común, glutamato monosódico, ajo, condimento unipack, extracto de verduras, humo líquido, pimienta, comino, orégano en polvo, laurel, poli-fosfato, curry, aceite vegetal y agua, almacenándose luego en refrigeración ( $\left.4^{\circ} \mathrm{C} / 3 \mathrm{~h}\right)$.

Evaluación microbiológica del enlatado

Para evaluar la calidad microbiológica se realizaron los siguientes análisis: Coliformes fecales, Staphylococcus aureus. De acuerdo a lo exigido por la NTC-1325 (6).

Prueba del tiempo de vida útil (TVU) del enlatado de conejo tipo troceado

Se realizó en base al método de vida útil a tiempo real. Se evaluó el efecto de la temperatura "normal" de conservación sobre las propiedades microbiológicas, físico-químicas y sensoriales de un alimento durante un periodo de tiempo, entendiéndose como temperatura normal, aquella que será empleada durante la conservación comercial del producto ${ }^{1}$. Evaluación sensorial del enlatado de conejo

El enlatado fue calentado previamente y evaluado por un Método Afectivo. Para desarrollar el método afectivo se utilizó la prueba de nivel de agrado, en donde se empleó una escala hedónica descriptiva estructurada con cinco puntos(7).

\section{Análisis estadístico}

Los resultados correspondientes a tres ensayos independientes se expresaron como el promedio \pm el error estándar de la media (ESM). Para la organización de los datos se empleó la hoja de cálculo MS Excel 2010, y para los análisis estadísticos el paquete GraphPad Prism V5.00 para Windows.

\section{RESULTADOS Y DISCUSIÓN}

El resultado de los análisis proximales y fisicoquímicos de la carne de conejo se muestra en la Tabla 1.

Tabla 1. Análisis proximal y fisicoquímicos de la carne de conejo

\begin{tabular}{cc}
\hline Parámetro & \\
\hline Proteína & $18 \%$ \\
Grasa & $3 \%$ \\
Fibra & $14 \%$ \\
Humedad & $12 \%$ \\
Cenizas & $0.38 \%$ \\
\hline
\end{tabular}




$\begin{array}{cc}\mathrm{pH} & 6.254 \\ \text { Potasio } & 490 \mathrm{mg} \\ \text { Hierro } & 0.8 \mathrm{mg} \\ \text { Sodio } & 57 \mathrm{mg}\end{array}$

La carne obtenida del conejo (Lepóridae) obtuvo un porcentaje de humedad menor al reportado por Cury et al.(1) y Pascual et al.(2) correspondiente a un 75,56 y $74,51 \%$ respectivamente, sin embargo, con relación al porcentaje de proteínas el valor obtenido es similar al reportado por los mismos autores con valores de 20,91 y $20,97 \%$.

Los valores de $\mathrm{pH}$ presentados son bajos debido a que las reservas de glucógeno se agotan antes del sacrificio, debido a que los animales sufrieron estrés con una intensidad sostenida durante un largo periodo, o bien, que los mismos hayan sido obligados a realizar un ejercicio físico prolongado (8). El mineral más abundante presente es el potasio con un valor de $490 \mathrm{mg}$.

El resultado del análisis funcional se muestra en la tabla 2, donde se observa que la capacidad de retención de agua (CRA), es de 0.8 , es decir, un $80 \%$ de agua está presente por $\mathrm{g}$ de carne, siendo mayor a la reportada por Rengifo y Ordoñez ${ }^{8}$, para pollo (22,5\%), cerdo $(21,66 \%)$, res $(22,91 \%)$ Ovino
$(22,91 \%)$ Conejo $(24,16 \%)$ y pescado Paco (25\%).

Tabla 2. Propiedades funcionales de la carne de conejo

\begin{tabular}{cc}
\hline Parámetro & Valor \\
\hline $\begin{array}{c}\text { Capacidad de retención de } \\
\text { agua (CRA) }\end{array}$ & 0,8 \\
Capacidad emulsificante & $10.42 \mathrm{~mL}$ \\
(CE) & \\
\hline
\end{tabular}

Los resultados del análisis microbiológico indicaron que no hubo presencia de carga microbiana en relación a coliformes totales y mesofilos aerobios, por lo tanto, al comparar con la normatividad vigente se puede decir que la carne de la iguana no presenta riesgo para la salud.

El tiempo de vida útil se estimò considerando las tres variables que poseen de mayor influencia sobre el producto a través del tiempo. Al analizar todos los parámetros, los resultados permitieron determinar que el enlatado de conejo tipo troceado tiene una vida de anaquel superior a 2 años.

Los resultados que arrojó la prueba del nivel de agrado en la valoración de las características organolépticas indicaron que el enlatado de conejo tipo troceado presentó los mejores 
57

resultados para los atributos de olor y sabor. Presentándose también una aceptación de dicho producto con valor de $66 \%$.

\section{CONCLUSIONES}

La carne de conejo presento un alto valor nutritivo, debido a su bajo contenido de grasas y su elevado contenido proteico, transformándose en una alternativa a la proteína animal para el consumo humano.

\section{AGRADECIMIENTOS}

Los autores agradecen a la Universidad de Cartagena y al SENA por facilitar espacio, recursos y tiempo de los investigadores.

\section{Referencias bibliográficas}

1. Cury K, Martínez A, Olivero R, Aguas $\mathrm{Y}$. Characterization of Rabbit meat and sausage production. Rev. Colombiana cienc. Anim. 2011; 3(2): 269 -282.

2. Pascual M, Aliaga S. Composición de la canal y de la carne en conejos seleccionados por velocidad de crecimiento. ITEA. 2005; 26(2): 807-809

3. González-Redondo P, CaravacaRodríguez F. Producción de conejos de aptitud cárnica. Sistemas de Producción Animal. Capítulo 30.,379-393. http://www.uco.es/zootecniaygestion/img/ pictorex/09 1034 Cunicultura.pdf
4. FA GUARNIZO, YPN MARTINEZ, BML PINZON (2012). Azúcares del pseudotallo de plátano: una opción para la obtención de alcohol de segunda generación. Revista Bistua, Vol. 10, no.1, 39-51.

5. Morillas-Ruiz JM, Delgado-Alarcón JM. Análisis nutricional de alimentos vegetales con diferentes orígenes: Evaluación de capacidad antioxidante y compuestos fenólicos totales. Nutr. clín. diet. hosp. 2012; 32(2):8-20.

6. Webb $\mathrm{N}$, Ivey $\mathrm{F}$, Craig $\mathrm{H}$, Jones, $\mathrm{V}$ Monroe. The measurement of emulsifying capacity by electrical resistance. Journal Food Science. 1970; 5 (4): 501-504.

7. Prieto, E. M., Alquisira, J. P., \& Alonso, C. R. (2013). Microwave and Ultrasound Activation Effect on Cationization of Corn and Potato Starches. Ciencia en Desarrollo, 4(1), 151-174.

8. NORMA TÉCNICA COLOMBIANA (NTC) 1325. 2008. (Quinta Actualización). Industrias alimentarias. Productos cárnicos procesados no enlatados. ICONTEX. http://tienda.icontec.org/brief/NTC1325.p df

9. Hleap JI, González JM, Mora MF. Evaluación bromatológica, sensorial y microbiológica de salchichas de tilapia roja (Oreochromis sp.) con adición de harina de lombriz (Eisenia Foetida). Vitae. 2012; 19(1): 210-212. 
10. Rengifo L, Ordóñez E. (2010). Efecto de la temperatura en la capacidad de retención de agua y $\mathrm{pH}$ en carne de pollo, ovino, conejo y pescado paco. http://www.guzlopeditoras.com/web_des/ing01/alimentaria/ pld0351.pdf 